\title{
Merancang Sistem untuk Meningkatkan Kinerja Sumber Daya Manusia Menggunakan Metode Analytical Hierarchi Process (AHP) di PTPN V PKS Sei Pagar
}

\author{
Suherman ${ }^{1}$, Benny Rakasiwi ${ }^{2}$ \\ ${ }^{1,2}$ Jurusan Teknik Industri, Fakultas Sains dan Teknologi, UIN Sultan Syarif Kasim Riau \\ E-mail : suher_aje@yahoo.co.id
}

\begin{abstract}
Abstrak
PTVN V PKS Sei Pagar merupakan BUMN yang bergerak dibidang pengolahan kelapa sawit menjadi CPO (Crude Palm Oil) dan inti sawit menjadi PKO (Palm Karnel Oil). Kinerja karyawan merupakan salah satu ukuran yang sering dipakai dalam menentukan efektifitas suatu perusahaan. Sebuah perusahaan tidak akan dapat berkembang apabila kinerja karyawannya juga tidak mengalami peningkatan apalagi dengan semakin tingginya tingkat persaingan yang ada pada dunia bisnis sekarang ini. Penelitian ini bertujuan untuk merancang sistem diperusahaan, penelitian pada tugas akhir ini menggunakan metode Analytical Hierarchi Process (AHP). Metode ini digunakan sebagai alat untuk menentukan sistem yang ingin dirancang, terdapat dua kriteria yang ingin dirancang yaitu variabel pelatihan dan variabel motivasi kerja, dengan menggunakan metode Analytical Hierarchi Process (AHP).Berdasarkan hasil penelitian didapat nilai prioritas tertinggi pada $\mathrm{P}_{1}$ yaitu sebesar $0,17, \mathrm{P}_{1}$ itu sendiri yaitu pertanyaan dari variabel pelatihan, maka dengan hasil ini peneliti melakukan perancangan sistem pada variabel pelatihan. Perancangan sistem pelatihan diberikan pada sembilan stasiun diantaranya yaitu stasiun Sortasi, Loading Ramp, Sterilizer, Hosting Crane, Thresing, Digester, Screw Press, Klarifikasi dan stasiun Boiler. Perancangan sistem yang diberikan yaitu tentang bagaimana melaksanakan prosedur kerja, apa saja yang perlu diperhatikan saat menggunakan mesin, mengontrol setiap komponen mesin agar tidak terjadi kebocoran serta kerusakan yang mengakibatkan cidera atau kecelakaan yang dapat merugikan diri sendiri maupun perusahaan.
\end{abstract}

Kata Kunci: Analytical Hierarchi Process (AHP), Crude Palm Oil (CPO),Palm Karnel Oil (PKO).

\section{Pendahuluan}

Banyak usaha yang dilakukan untuk meningkatkan kinerja Sumber Daya Manusia (SDM), diantaranya melalui kegiatan pelatihan. Kegiatan pelatihan merupakan proses memberikan atau meningkatkan kemampuan dan keterampilan serta menanamkan sikap kepada karyawan dimana proses tersebut akan sangat membantu karyawan dalam mengkoreksi kekurangan-kekurangan kerjanya di masa silam sehingga karyawan tersebut dapat meningkatkan kinerjanya dalam bekerja. Disamping itu pelaksanaan pelatihan memerlukan biaya yang tidak sedikit maka diperlukan suatu perencanaan yang matang, sistematis dan terarah dengan baik agar dana yang dikeluarkan tidak sia-sia melainkan dapat meningkatkan prestasi kerja karyawan yang pada akhirnya akan memberikan kontribusi yang positif bagi kemajuan perusahaan.

Kegiatan pelatihan merupakan sebuah proses mengajarkan pengetahuan dan keahlian tertentu serta sikap agar karyawan semakin terampil dan mampu melaksanakan tanggung jawab dengan baik,sesuai dengan standar kerja. Kegiatan pelatihan juga dimaksudkan untuk mengurangi kesenjangan antara sumber daya yang dimiliki perusahaan dengan sumber daya manusia yang diharapkan perusahaan agar perusahaan dapat mencapai tujuan, visi dan misi. Pelatihan merupakan suatu keharusan dari suatu organisasi karena semakin terdidik dan terlatihnya teknisi maka semakin tinggi pula produktivitas kerja. Pada umumnya setiap perusahaan memberikan berbagai macam pelatihan untuk karyawannya termasuk pada PTPN V PKS Sei Pagar.

Berdasarkan informasi dari asisten teknik dan hasil observasi yang dilakukan pada lini produksi diketahui beberapa kekurangan operator dalam menjalankan tugasnya seperti operator hanya mampu mengoperasikan satu jenis mesin saja dan belum memiliki kemampuan untuk mengoperasikan jenis mesin yang lainnya. Namun disisi lain, perusahaan mengharapkan operator mampu bekerja pada setiap lini produksi karena hal tersebut memudahkan perusahaan ketika melakukan proses rotasi pada karyawan atau dapat menggantikan tugas operator lain ketika sedang berhalangan hadir.

Selain itu kemampuan pekerja masih sebatas mampu mengoperasikan mesin namun belum dapat melakukan perbaikan. Hal tersebut 
terlihat jelas pada saat mesin mengalami kerusakan, operator belum mampu melakukan perbaikan terhadap mesin tersebut sehingga perusahaan menggunakan teknisi untuk memperbaikinya sehingga kegiatan produksi terganggu, hal ini merupakan salah satu faktor penyebab dari menurunnya kinerja SDM serta dapat mengakibatkan target produksi tidak tercapai yang dapat dilihat pada Gambar berikut.

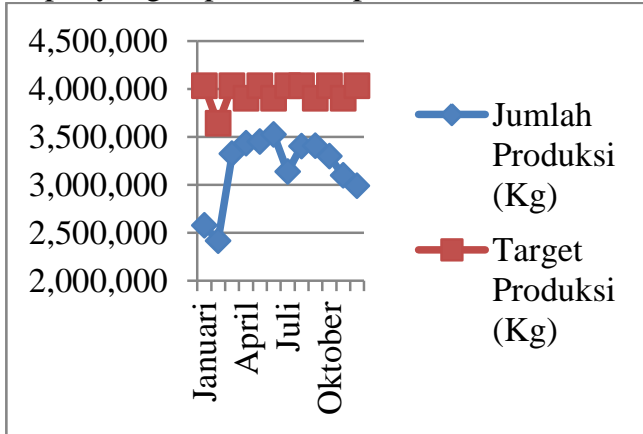

Gambar 1.1 Grafik Data Perbandingan Jumlah Produksi dengan Target Produsi Tahun 2014

Dari Gambar 1.1 dapat dilihat bahwa terdapat perbedaan antara jumlah produksi dengan target produksi untuk setiap periodenya, terutama pada periode Februari terdapat perbedaan yang signifikan antara jumlah produksi dengan target produksi yang ingin dicapai. Sehingga berdasarkan latar belakang di atas perlu merancang sistem untuk meningkatkan kinerja SDM di PTPN V PKS Sei Pagar. Merancang sistem dilakukan menggunakan metode AHP (analytical hierarchi process) dengan metode ini nantinya dapat memprioritaskan masalah yang ada dan kemudian merancang sistem yang lebih baik, karena untuk saat ini belum ada sistem yang tertulis dalam upaya meningkatkan kinerja karyawan, untuk saat ini hanya sebatas apel pagi, arahan-arahan serta himbauan agar dapat bekerja dengan baik. Sehingga melalui rancangan ini diharapkan dapat memperbaiki yang berkaitan dengan pengetahuan, keterampilan dan sikap karyawan dalam menjalankan tugasnya untuk mencapai tujuan perusahaan.

\section{Tinjauan Pustaka}

\section{Metode AHP (Analytic Hierarchy Proses)}

Metode AHP (Analytic Hierarchy Proses) dikembangkan oleh prof. Thomas Lorie Saaty dari Wharston Businiess school untuk mencari ranking atau urutan prioritas dari berbagai alternatif dalam pemecahan suatu permasalahan. Dalam kehidupan sehari-hari, seseorang senantiasa dihadapkan untuk melakukan pilihan dari berbagai alternatif. Disini diperlukan penentuan prioritas dan uji konsistensi terhadap pilihan-pilihan yang telah dilakukan. Dalam situasi yang kompleks, pengambilan keputusan tidak di pengaruhi oleh satu faktor saja melainkan multifaktor dan mencakup berbagai jenjang maupun kepentingan.

\section{Tahapan AHP (Analytic Hierarchy Proses)}

1. Mendefinisikan masalah dan menentukan solusi yang diinginkan. Dalam tahap ini kita berusaha menentukan masalah yang akan kita pecahkan secara jelas, detail dan mudah dipahami. Dari masalah yang ada kita coba tentukan solusi yang mungkin cocok bagi masalah tersebut. Solusi dari masalah mungkin berjumlah lebih dari satu. Solusi tersebut nantinya kita kembangkan lebih lanjut dalam tahap berikutnya.

2. Membuat struktur hierarki yang diawali dengan tujuan utama.

Setelah menyusun tujuan utama sebagai level teratas akan disusun level hierarki yang berada di bawahnya yaitu kriteria-kriteria yang cocok untuk mempertimbangkan atau menilai alternatif yang kita berikan dan menentukan alternatif tersebut. Tiap kriteria mempunyai intensitas yang berbedabeda. Hirarki dilanjutkan dengan subkriteria (jika mungkin diperlukan).

3. Membuat matrik perbandingan berpasangan yang menggambarkan kontribusi relatif atau pengaruh setiap elemen terhadap tujuan atau kriteria yang setingkat di atasnya.

4. Melakukan perbandingan berpasangan sehingga diperoleh jumlah penilaian seluruhnya sebanyak n x [(n-1)/2] buah, dengan $\mathrm{n}$ adalah banyaknya elemen yang dibandingkan.

\section{Hirarki}

Hirarki adalah gambaran dari permasalahan yang kompleks dalam struktur banyak tingkat dimana dimana tingkat paling atas adalah tujuan dan diikuti tingkat kriteria, subkreteria dan seterusnya kebawah sampai pada tingkat paling bawah yaitu tingkat alternatif. Hirarki menggambarkan secara grafis saling ketergantungan elemen-elemen yang relevan, memperlihatkan hubungan antar elemen yang homogen dan hubungan dengan sistem sehingga menjadi satu kesatuan yang utuh. Struktur AHP dapat dilihat pada gambar berikut.

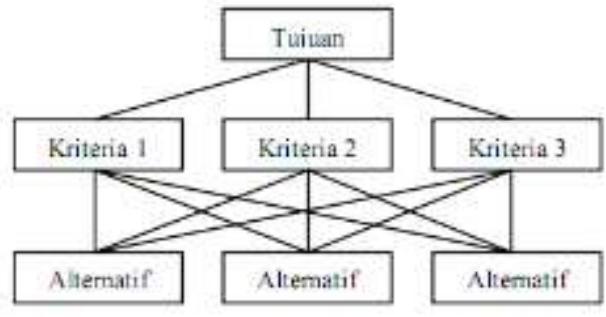

Gambar 2.1 Hirarki Model AHP 


\section{Matriks Perbandingan Berpasangan}

Langkah awal untuk menentukan susunan prioritas elemen adalah menyusun perbandingan berpasangan

Tabel 2.1 Skala Penilaian Perbandingan Berpasangan

\begin{tabular}{|c|c|c|}
\hline $\begin{array}{c}\text { Tingkat } \\
\text { kepentingan }\end{array}$ & Definisi & Keterangan \\
\hline 1 & $\begin{array}{l}\text { Sama } \\
\text { pentingnya }\end{array}$ & $\begin{array}{l}\text { Kedua elemen } \\
\text { mempunyai } \\
\text { pengaruh yang } \\
\text { sama. }\end{array}$ \\
\hline 3 & $\begin{array}{l}\text { Agak lebih } \\
\text { penting } \\
\text { yang satu } \\
\text { atas yang } \\
\text { lainnya }\end{array}$ & $\begin{array}{l}\text { Pengalaman dan } \\
\text { penilaian sangat } \\
\text { memihak satu } \\
\text { elemen } \\
\text { dibandingkan } \\
\text { dengan } \\
\text { pasangannya. }\end{array}$ \\
\hline 5 & $\begin{array}{l}\text { Cukup } \\
\text { penting }\end{array}$ & $\begin{array}{ll}\text { Pengalaman } & \text { dan } \\
\text { keputusan } & \\
\text { menunjukan } & \\
\text { kesukaan } & \text { atas } \\
\text { aktifitas lebih } & \text { dari } \\
\text { yang lain. } & \end{array}$ \\
\hline 7 & $\begin{array}{l}\text { Sangat } \\
\text { penting }\end{array}$ & $\begin{array}{l}\text { Satu elemen mutlak } \\
\text { lebih disukai } \\
\text { dibandingkan } \\
\text { dengan } \\
\text { pasangannya, pada } \\
\text { tingkat keyakinan } \\
\text { tertinggi. }\end{array}$ \\
\hline 9 & $\begin{array}{l}\text { Mutlak } \\
\text { lebih } \\
\text { penting }\end{array}$ & $\begin{array}{l}\text { Satu elemen mutlak } \\
\text { lebih disukai } \\
\text { dibandingkan } \\
\text { dengan } \\
\text { pasangannya, pada } \\
\text { tingkat keyakinan } \\
\text { tertinggi. }\end{array}$ \\
\hline $2,4,6,8$ & $\begin{array}{l}\text { Nilai } \\
\text { tengah } \\
\text { diantara } \\
\text { dua nilai } \\
\text { keputusan } \\
\text { yang } \\
\text { berdekatan } \\
\end{array}$ & $\begin{array}{l}\text { Bila kompromi } \\
\text { dibutuhkan. }\end{array}$ \\
\hline Resiprokal & Kebalikan & \begin{tabular}{lr} 
Jika elemen & $i$ \\
memiliki salah & satu \\
angka dari & skala \\
perbandingan & 1 \\
sampai 9 yang telah & \\
ditetapkan & oleh \\
saaty ketika & \multicolumn{2}{c}{ dibandingkan } \\
dengan elemen $j$, \\
maka $j$ memiliki \\
kebalikannya ketika
\end{tabular} \\
\hline
\end{tabular}

\begin{tabular}{|c|l|l|}
\hline & & $\begin{array}{l}\text { dibandingkan } \\
\text { dengan elemen } i .\end{array}$ \\
\hline Rasio & $\begin{array}{l}\text { Rasio yang } \\
\text { didapat } \\
\text { langsung } \\
\text { dari } \\
\text { pengukuran }\end{array}$ & \\
\hline
\end{tabular}

Misalkan kriteria $\mathrm{C}$ memiliki beberapa elemen dibawahnya, yaitu $A_{1}, A_{2}, \ldots A_{n}$. Tabel matriks perbandingan berpasangan berdasarkan kriteria $\mathrm{C}$ sebagai berikut.

Tabel 2.2 Matriks Perbandingan Berpasangan

\begin{tabular}{|c|c|c|c|}
\hline $\mathrm{C}$ & $\mathrm{A}_{1}$ & $\mathrm{~A}_{2}$ & $\mathrm{~A}_{\mathrm{n}}$ \\
\hline $\mathrm{A}_{1}$ & 1 & $\ldots$ & $\mathrm{A}_{1 \mathrm{n}}$ \\
\hline $\mathrm{A}_{2}$ & $\mathrm{~A}_{21}$ & 1 & $\ldots$ \\
\hline $\mathrm{A}_{\mathrm{n}}$ & $\ldots$ & $\ldots$ & 1 \\
\hline
\end{tabular}

$\mathrm{C}$ adalah kriteria yang digunakan sebagai dasar perbandingan. $\mathrm{A}_{1}, \mathrm{~A}_{2}, \ldots . \mathrm{A}_{\mathrm{n}}$ adalah elemenelemen pada satu tingkat dibawah $\mathrm{C}$. Elemen kolom sebelah kiri selalu dibandingkan dengan elemen baris puncak. Nilai kebalikan diberikan kepada elemen baris ketika tampil sebagai elemen kolom dan elemen kolom tampil sebagai elemen baris. Dalam matriks ini terdapat perbandingan dengan elemen itu sendiri pada diagonal utama dan bernilai 1 .

\section{Konsistensi Matriks Perbandingan} Berpasangan

Apabila A adalah matriks perbandingan berpasangan yang konsisten maka semua nilai eigen bernilai nol kecuali yang bernilai sama dengan $n$. Tetapi bila $\mathrm{A}$ adalah matriks tak konsisten, variasi kecil atas $\alpha_{\text {ij }}$ akan membuat nilai eigen terbesar $\lambda_{\text {maks }}$ selalu lebih besar atau sama dengan $\mathrm{n}$ yaitu $\lambda_{\text {maks }} \geq n$. Perbedaan antara $\lambda_{\text {maks }}$ dengan $\mathrm{n}$ dapat digunakan untuk meneliti seberapa besar ketidakkonsistennan yang ada dalam A, dimana rata-ratanya dinyatakan sebagai berikut.

$$
\mathrm{CI}=\frac{\lambda_{\text {maks }}-\mathrm{n}}{\mathrm{n}-1}
$$

Suatu metriks perbandingan berpasangan dinyatakan konsisten apabila nilai consistency ratio $(\mathrm{CR}) \leq 10 \%$. $\mathrm{CR}$ dapat dihitung menggunakan rumus sebagai berikut:

$$
\mathrm{CR}=\frac{\mathrm{CI}}{\mathrm{RI}}
$$

Berikut tabel Random Index (RI) untuk matriks berukuran 1 sampai 15 : 


\section{Metode Penelitian}

\section{Populasi dan Sampel}

Populasi dalam penelitian ini adalah total operator pada PTPN V PKS Sei Pagar yaitu sebanyak 18 orang. Untuk penelitian ini teknik sampling yang digunakan adalah teknik sampling jenuh/sensus yaitu teknik yang dilakukan dengan menjadikan seluruh anggota populasi menjadi sampel.

\section{Hasil dan Pembahasan}

\section{Memberikan Nilai Perbandingan}

Kriteria yang digunakan dalam penelitian ini adalah pelatihan yang terdiri dari kemampuan dan pengetahuan. Motivasi kerja terdiri dari motif, harapan dan insentif. Dari kriteria tersebut terdapat 15 pertanyaan yang akan di masukan kedalam matriks perbandingan. Adapun matrik nilai perbandingan berpasangan untuk meningkatkan kinerja karyawan disajikan pada Tabel 1.

\section{Menghitung Sintesa Prioritas}

Matriks ini diperoleh dengan rumus yaitu nilai baris dibagi jumlah masing-masing kolom lama. Sedangkan nilai prioritas didapat dari nilai pada baris jumlah dibagi dengan banyaknya kriteria. Hasil Sintesa Prioritas dapat dilihat pada Tabel 2.

Misal :

$$
\begin{array}{ll}
\text { a. } & \mathrm{P}_{1}=\frac{\text { Nilai Kolom }}{\text { Nilai Jumlah Kolom }} \\
= & \frac{1}{4,53}=0,22 \\
\text { b. } & \text { Prioritas }=\frac{\text { Jumlah Baris }}{\text { Jumlah Kriteria }} \\
= & \frac{2,66}{15}=0,17
\end{array}
$$

\section{Perhitungan Rasio Konsistensi}

Perhitungan ini digunakan untuk memastikan bahwa nilai rasio konsistensi (CR) kurang sama dengan 0,1. Jika ternyata nilai CR lebih besar dari 0,1 maka matriks perbandingan berpasangan harus diperbaiki. Untuk perhitungannya yaitu total prioritas x jumlah matriks. Hasil perhitungan Rasio Konsistensi disajikan pada Tabel 3.

$$
\begin{aligned}
& \text { a. } \quad \lambda \max =\frac{\text { jumlah matriks }}{\text { Jumlah kriteria }} \\
& \text { b. } \quad \mathrm{CI}=\frac{\lambda \max -\mathrm{n}}{\mathrm{n}-1} \\
& \mathrm{CI}=\frac{16,95-15}{15-1}=0,14
\end{aligned}
$$

c. $\quad \mathrm{CR}=\frac{\mathrm{CI}}{\mathrm{RI}}, \mathrm{RI}$ adalah orde matriks yang digunakan yaitu matriks $15=1,59$

$\mathrm{CR}=\frac{0,14}{1,59}=0,08$

$\mathrm{CR} \leq 0,1$, yaitu $0,08 \leq 0,1$

\section{Hasil Perancangan}

Berdasarkan perhitungan sintesa prioritas nilai tertinggi terdapat pada $\mathrm{P}_{1}$ dengan nilai 0,17 sehingga berdasarkan perhitungan ini perancangan dilakukan pada $\mathrm{P}_{1} . \mathrm{P}_{1}$ adalah pertanyaan dari variabel pelatihan dengan demikian pelatihan perlu dilakukan perancangan dalam upaya meningkatkan kinerja karyawan. Hasil rancangan pelatihan dapat dilihat pada Tabel 4.

\section{Kesimpulan}

Berdasarkan tujuan penelitian yang telah disampaikan dapat ditarik kesimpulan sebagai berikut :

1. Sintesa prioritas yang tertinggi yaitu pada $\mathrm{P}_{1}$ sebesar 0,17 nilai ini didapat dari hasil perhitungan menggunakan metode Analytical Hierarchy Process (AHP), sehingga perancangan yang dilakukan sesuai dengan $\mathrm{P}_{1}$ yaitu variabel pelatihan. Perancangan ini diharapkan nantinya dapat membantu perusahaan dalam meningkatkan kinerja karyawan.

2. Berdasarkan perhitungan sintesa prioritas kemudian dirancang sistem pelatihan untuk meningkatkan kinerja. Rancangan tersebut dimulai dari stasiun sortasi, stasiun loading ramp, stasiun sterilizer, stasiun hosting crane, stasiun thresing, stasiun screw press, stasiun klarifikasi dan stasiun boiler.

Berdasarkan penelitian yang dilakukan di PTPN V PKS Sei Pagar adapun saran yang dapat diberikan adalah:

1. Dengan adanya laporan penelitian ini penulis mengharapkan adanya manfaat bagi semua pihak, khususnya bagi pihak perusahaan yaitu sebagai bahan masukan dan pertimbangan dalam menentukan pelatihan yang akan diberikan kepada operator.

2. Perusahaan perlu menanamkan kesadaran kepada seluruh karyawan untuk dapat ikut serta berperan aktif dalam peningkatan kinerja baik bagi diri sendiri maupun bagi perusahaan.

Hasil rancangan tidak menutup kemungkinan untuk diciptakannya inovasi baru, dan diharapkan 
ada yang mengembangkannya yang lebih baik lagi dimasa yang akan datang.

\section{Daftar Pustaka}

Agusta, Leonando dan Sutanto, Eddy Madiono. Pengaruh Pelatihan dan Motivasi Kerja Terhadap Kinerja Karyawan CV Haragon Surabaya. Jurnal Manajemen Bisnis. Surabaya:2013.

Ahmad, Rizal. Hubungan Pelatihan dan Pengembangan Yang Diterapkan Oleh Bina Cendikia Agung (Bica) Panca Budi dengan Kinerja Pegawai yang ada Dilingkungan UNPAB (Kampus Panca Budi) Medan. Jurnal Ekonomi. Medan:2008.

Dalmy, Darlisman. Pengaruh SDM, Komitmen, Motivasi Terhadap kinerja Auditor dan Reward sebagai Variabel Moderating pada Inspektorat Provinsi Jambi.Tesis Program Pascasarjana USU. Medan:2009.

Salmah, Ninin Non Ayu. Pengaruh Program Pelatihan dan Pengembangan Karyawan Terhadap Kompetensi Karyawan pada PT. Muba Electric Power Sekayu. Jurnal Ekonomi dan Informasi Akuntansi (JENIUS). Palembang:2012.

Sinay, Philipus. Analisis Faktor-Faktor yang Mempengaruhi Kinerja Karyawan pada PT. Bumakumawa Di Kota Sorong. Jurnal Ekonomi. Sorong:2009.

Siregar, Sahat. Pengaruh Pengembangan SDM Terhadap Kinerja Pegawai (studikasus pada dinas perhubungan kota medan). Skripsi Program Ilmu Administrasi Negara. Medan:2009.

Taylor, Bernard. Manajement Science Edisi 8. Salemba Empat. Jakarta:2005.

Umar, Husein. Desain Penelitian MSDM dan Perilaku Karyawan: Paradigma Positivistik dan Berbasis Pemecahan Masalah. RajawaliPers. Jakarta:2010.

Wibisono, Dermawan. Manajemen Kinerja. Erlangga. Jakarta:2006.

Wijayanti, Annisa dan Wimbarti, Supra. Evaluasi dan Pengembangan Sistem Penilaian Kinerja Pada PT HKS. Jurnal Psikologi Undip. Yogyakarta:2012. 
Tabel 1. Matrik Perbandingan Berpasangan

\begin{tabular}{|c|c|c|c|c|c|c|c|c|c|c|c|c|c|c|c|}
\hline & $\mathrm{P}_{1}$ & $\mathrm{P}_{2}$ & $\mathrm{P}_{3}$ & $\mathrm{P}_{4}$ & $\mathrm{P}_{5}$ & $\mathrm{P}_{6}$ & $\mathrm{P}_{7}$ & $\mathrm{P}_{8}$ & $\mathrm{P}_{9}$ & $\mathrm{P}_{10}$ & $\mathrm{P}_{11}$ & $\mathrm{P}_{12}$ & $\mathrm{P}_{13}$ & $\mathrm{P}_{14}$ & $\mathrm{P}_{15}$ \\
\hline$P_{1}$ & 1,00 & 4,00 & 6,00 & 3,00 & 5,00 & 7,00 & 4,00 & 3,00 & 4,00 & 5,00 & 3,00 & 7,00 & 2,00 & 4,00 & 5,00 \\
\hline $\mathrm{P}_{2}$ & 0,25 & 1,00 & 3,00 & 5,00 & 4,00 & 6,00 & 2,00 & 4,00 & 5,00 & 7,00 & 4,00 & 3,00 & 6,00 & 5,00 & 3,00 \\
\hline $\mathrm{P}_{3}$ & 0,16 & 0,33 & 1,00 & 4,00 & 3,00 & 5,00 & 7,00 & 4,00 & 3,00 & 8,00 & 5,00 & 6,00 & 3,00 & 5,00 & 2,00 \\
\hline $\mathrm{P}_{4}$ & 0,33 & 0,50 & 0,25 & 1,00 & 4,00 & 7,00 & 4,00 & 3,00 & 5,00 & 4,00 & 6,00 & 5,00 & 3,00 & 2,00 & 4,00 \\
\hline $\mathrm{P}_{5}$ & 0,20 & 0,20 & 0,33 & 0,25 & 1,00 & 6,00 & 4,00 & 3,00 & 5,00 & 6,00 & 7,00 & 5,00 & 3,00 & 4,00 & 5,00 \\
\hline $\mathrm{P}_{6}$ & 0,14 & 0,16 & 0,20 & 0,14 & 0,16 & 1,00 & 2,00 & 4,00 & 3,00 & 5,00 & 6,00 & 3,00 & 4,00 & 3,00 & 2,00 \\
\hline $\mathrm{P}_{7}$ & 0,25 & 0,50 & 0,14 & 0,25 & 0,25 & 0,50 & 1,00 & 5,00 & 4,00 & 3,00 & 5,00 & 4,00 & 3,00 & 2,00 & 3,00 \\
\hline $\mathrm{P}_{8}$ & 0,33 & 0,25 & 0,25 & 0,33 & 0,33 & 0,25 & 0,20 & 1,00 & 2,00 & 3,00 & 4,00 & 5,00 & 3,00 & 2,00 & 4,00 \\
\hline $\mathrm{P}_{9}$ & 0,25 & 0,20 & 0,33 & 0,20 & 0,20 & 0,33 & 0,25 & 0,50 & 1,00 & 3,00 & 5,00 & 4,00 & 6,00 & 5,00 & 6,00 \\
\hline$P_{10}$ & 0,20 & 0,14 & 0,12 & 0,25 & 0,16 & 0,20 & 0,33 & 0,33 & 0,33 & 1,00 & 4,00 & 3,00 & 2,00 & 5,00 & 3,00 \\
\hline $\mathrm{P}_{11}$ & 0,33 & 0,25 & 0,20 & 0,16 & 0,14 & 0,16 & 0,20 & 0,25 & 0,20 & 0,25 & 1,00 & 2,00 & 3,00 & 3,00 & 4,00 \\
\hline $\mathrm{P}_{12}$ & 0,14 & 0,33 & 0,16 & 0,20 & 0,20 & 0,33 & 0,25 & 0,20 & 0,25 & 0,33 & 0,50 & 1,00 & 2,00 & 3,00 & 2,00 \\
\hline $\mathrm{P}_{13}$ & 0,50 & 0,16 & 0,33 & 0,33 & 0,33 & 0,25 & 0,33 & 0,33 & 0,16 & 0,5 & 0,33 & 0,50 & 1,00 & 2,00 & 2,00 \\
\hline $\mathrm{P}_{14}$ & 0,25 & 0,20 & 0,20 & 0,50 & 0,25 & 0,33 & 0,50 & 0,50 & 0,20 & 0,2 & 0,33 & 0,33 & 0,50 & 1,00 & 2,00 \\
\hline $\mathrm{P}_{15}$ & 0,20 & 0,33 & 0,50 & 0,25 & 0,20 & 0,50 & 0,33 & 0,25 & 0,16 & 0,33 & 0,25 & 0,50 & 0,50 & 0,50 & 1,00 \\
\hline Jumlah & 4,53 & 8,55 & 13,01 & 15,86 & 19,22 & 34,85 & 26,39 & 29,36 & 33,3 & 46,61 & 51,41 & 49,33 & 42 & 46,6 & 48 \\
\hline
\end{tabular}

Tabel 2. Sintesa Prioritas Perbandingan Berpasangan

\begin{tabular}{|c|c|c|c|c|c|c|c|c|c|c|c|c|c|c|c|c|c|}
\hline & $\mathrm{P}_{1}$ & $\mathrm{P}_{2}$ & $\mathrm{P}_{3}$ & $\mathrm{P}_{4}$ & $\mathrm{P}_{5}$ & $\mathrm{P}_{6}$ & $\mathrm{P}_{7}$ & $\mathrm{P}_{8}$ & $\mathrm{P}_{9}$ & $\mathrm{P}_{10}$ & $\mathrm{P}_{11}$ & $\mathrm{P}_{12}$ & $\mathrm{P}_{13}$ & $\mathrm{P}_{14}$ & $\mathrm{P}_{15}$ & Jumlah & Prioritas \\
\hline $\mathrm{P}_{1}$ & 0,22 & 0,46 & 0,46 & 0,18 & 0,26 & 0,2 & 0,15 & 0,10 & 0,12 & 0,10 & 0,05 & 0,14 & 0,04 & 0,08 & 0,10 & 2,66 & 0,17 \\
\hline $\mathrm{P}_{2}$ & 0,05 & 0,11 & 0,23 & 0,31 & 0,20 & 0,17 & 0,07 & 0,13 & 0,15 & 0,15 & 0,07 & 0,06 & 0,14 & 0,10 & 0,06 & 2,00 & 0,13 \\
\hline $\mathrm{P}_{3}$ & 0,03 & 0,03 & 0,07 & 0,25 & 0,15 & 0,14 & 0,26 & 0,13 & 0,09 & 0,17 & 0,09 & 0,12 & 0,07 & 0,10 & 0,04 & 1,74 & 0,11 \\
\hline $\mathrm{P}_{4}$ & 0,07 & 0,05 & 0,02 & 0,06 & 0,20 & 0,20 & 0,15 & 0,10 & 0,15 & 0,08 & 0,11 & 0,10 & 0,07 & 0,04 & 0,08 & 1,48 & 0,09 \\
\hline $\mathrm{P}_{5}$ & 0,04 & 0,02 & 0,02 & 0,015 & 0,05 & 0,17 & 0,15 & 0,10 & 0,15 & 0,12 & 0,13 & 0,10 & 0,07 & 0,08 & 0,10 & 1,31 & 0,08 \\
\hline $\mathrm{P}_{6}$ & 0,03 & 0,02 & 0,02 & 0,008 & 0,008 & 0,02 & 0,07 & 0,13 & 0,09 & 0,10 & 0,11 & 0,06 & 0,09 & 0,06 & 0,04 & 0,85 & 0,056 \\
\hline $\mathrm{P}_{7}$ & 0,05 & 0,05 & 0,01 & 0,015 & 0,013 & 0,014 & 0,03 & 0,17 & 0,12 & 0,06 & 0,09 & 0,08 & 0,07 & 0,04 & 0,06 & 0,87 & 0,06 \\
\hline $\mathrm{P}_{8}$ & 0,07 & 0,03 & 0,02 & 0,02 & 0,017 & 0,007 & 0,007 & 0,03 & 0,06 & 0,06 & 0,07 & 0,10 & 0,07 & 0,04 & 0,08 & 0,68 & 0,04 \\
\hline $\mathrm{P}_{9}$ & 0,05 & 0,02 & 0,02 & 0,012 & 0,01 & 0,009 & 0,009 & 0,017 & 0,03 & 0,06 & 0,09 & 0,08 & 0,14 & 0,10 & 0,12 & 0,76 & 0,05 \\
\hline $\mathrm{P}_{10}$ & 0,04 & 0,01 & 0,01 & 0,015 & 0,025 & 0,005 & 0,012 & 0,01 & 0,009 & 0,02 & 0,07 & 0,06 & 0,04 & 0,10 & 0,06 & 0,49 & 0,03 \\
\hline $\mathrm{P}_{11}$ & 0,07 & 0,02 & 0,01 & 0,01 & 0,007 & 0,004 & 0,007 & 0,008 & 0,006 & 0,005 & 0,01 & 0,04 & 0,07 & 0,06 & 0,08 & 0,41 & 0,027 \\
\hline
\end{tabular}




\begin{tabular}{|c|c|c|c|c|c|c|c|c|c|c|c|c|c|c|c|c|c|}
\hline $\mathrm{P}_{12}$ & 0,03 & 0,03 & 0,01 & 0,012 & 0,01 & 0,009 & 0,009 & 0,006 & 0,007 & 0,007 & 0,009 & 0,02 & 0,04 & 0,06 & 0,04 & 0,30 & 0,019 \\
\hline $\mathrm{P}_{13}$ & 0,11 & 0,02 & 0,02 & 0,02 & 0,017 & 0,007 & 0,012 & 0,01 & 0,004 & 0,01 & 0,006 & 0,01 & 0,02 & 0,04 & 0,04 & 0,34 & 0,02 \\
\hline $\mathrm{P}_{14}$ & 0,05 & 0,02 & 0,01 & 0,03 & 0,013 & 0,009 & 0,018 & 0,017 & 0,006 & 0,004 & 0,006 & 0,006 & 0,01 & 0,02 & 0,04 & 0,26 & 0,017 \\
\hline $\mathrm{P}_{15}$ & 0,04 & 0,03 & 0,03 & 0,015 & 0,01 & 0,014 & 0,012 & 0,008 & 0,004 & 0,007 & 0,004 & 0,01 & 0,01 & 0,01 & 0,02 & 0,22 & 0,015 \\
\hline
\end{tabular}

(Sumber : Pengolahan Data, 2015)

Tabel 3. Rasio Konsistensi Perbandingan Berpasangan Kriteria

\begin{tabular}{|c|c|c|c|c|c|c|c|c|c|c|c|c|c|c|c|c|c|c|c|c|c|c|c|c|c|c|c|c|c|c|c|c|}
\hline & $\begin{array}{c}\mathrm{P}_{1} \\
0,17\end{array}$ & $\begin{array}{c}\mathrm{P}_{2} \\
0,18\end{array}$ & $\begin{array}{l}P_{3} \\
0,11\end{array}$ & $\begin{array}{c}P_{4} \\
0,09\end{array}$ & $\begin{array}{c}\mathrm{P}_{5} \\
0,08\end{array}$ & $\begin{array}{l}\mathrm{P}_{6} \\
0,056\end{array}$ & $\begin{array}{l}\mathrm{P}_{r} \\
0,06\end{array}$ & $\begin{array}{l}\mathrm{P}_{\mathrm{s}} \\
0,04\end{array}$ & $\begin{array}{l}P_{0} \\
0,05\end{array}$ & $\begin{array}{ll}\mathrm{P}_{10} \\
\mathrm{P}_{0,0}\end{array}$ & $\begin{array}{l}\mathrm{P}_{11} \\
0,027\end{array}$ & $\begin{array}{l}\mathrm{P}_{12} \\
0,019\end{array}$ & $\begin{array}{l}P_{13} \\
0,02\end{array}$ & $\begin{array}{c}P_{14} \\
0,017\end{array}$ & $\begin{array}{l}P_{15} \\
0,015\end{array}$ & $\mathrm{P}_{\mathrm{t}}$ & $\mathrm{P}_{3}$ & $\mathrm{P}_{3}$ & $\mathrm{P}_{\mathrm{s}}$ & $\mathrm{P}_{s}$ & $\mathrm{P}_{6}$ & $\mathrm{P}_{7}$ & $\mathrm{P}_{\mathrm{s}}$ & $\mathrm{P}_{P_{9}}$ & $\mathrm{P}_{10}$ & $\mathrm{P}_{\mathrm{u}}$ & $\mathrm{P}_{12}$ & $P_{B B}$ & $\mathrm{P}_{h / 4}$ & $\mathrm{P}_{\mathrm{ts}}$ & Jumlah & Jumlah \\
\hline$P_{1}$ & 1,00 & \begin{tabular}{|l}
4,00 \\
\end{tabular} & 6,00 & $\begin{array}{l}3,00 \\
\end{array}$ & 5,00 & 7,00 & 4,00 & 3,00 & 4,00 & 5,00 & 3,00 & 7,00 & 2,00 & 4,00 & 5,00 & \begin{tabular}{l|l}
0,17 \\
\end{tabular} & \begin{tabular}{l|l}
0.52 \\
\end{tabular} & 0,66 & \begin{tabular}{l|l}
0,27 \\
\end{tabular} & \begin{tabular}{l|l|l|l|}
0,40 & \\
\end{tabular} & 0,39 & 0,24 & 0,12 & 0,2 & 0,15 & 0,08 & \begin{tabular}{l|l|}
0,08 \\
\end{tabular} & 0,13 & 0,06 & 0,07 & & 0,82 \\
\hline $\mathrm{P}_{2}$ & 0,25 & 1,00 & 3,00 & \begin{tabular}{|l}
5,000 \\
\end{tabular} & 4,00 & 6,00 & 2,00 & 4,00 & 5,00 & 7,00 & 4,00 & 3,00 & 6,00 & 5,00 & 3,00 & 0,04 & 0,13 & 0,33 & 0,045 & 0,32 & 0,33 & 0,12 & 0,16 & 0,25 & 0,21 & 0,01 & 0,10 & 0,05 & 0,08 & 0,04 & 2,62 & 4,55 \\
\hline$P_{3}$ & 0,16 & 0,33 & 1,00 & 4,00 & 3,00 & 5,00 & 7,00 & 4,00 & 3,00 & 8,00 & 5,00 & 6,00 & 3,00 & 5,00 & 2,00 & 0,02 & \begin{tabular}{|l|l|}
0,04 \\
\end{tabular} & 0,11 & 0,36 & \begin{tabular}{l|l}
0,24 \\
\end{tabular} & 0,28 & 0,42 & 0,16 & 0,15 & 0,24 & 0,013 & \begin{tabular}{l|l}
0,10 \\
\end{tabular} & 0,11 & 0,08 & 0,03 & & 1,36 \\
\hline$P_{4}$ & 0,33 & 0,50 & 0,25 & $\begin{array}{l}1,00 \\
\end{array}$ & 4,00 & 7,00 & 4,00 & 3,00 & 5,00 & 4,00 & 6,00 & 5,00 & 3,00 & 2,00 & 4,00 & 0,05 & 0,06 & 0,02 & 0,09 & 0,32 & 0,39 & 0,24 & 0,12 & 0,25 & 0,12 & 0,016 & 0,04 & 0,09 & 0,03 & 0.06 & & 1,00 \\
\hline $\mathrm{Ps}_{s}$ & 0,20 & \begin{tabular}{|l}
0,20 \\
\end{tabular} & 0,33 & 0,25 & 1,00 & 6,00 & 4,00 & 3,00 & 5,00 & 6,00 & 7,00 & 5,00 & 3,00 & 4,00 & 5,00 & 0,03 & 0,02 & 0,03 & 0,02 & 0,08 & 0,33 & 0,24 & 0,12 & 0,25 & 0,18 & 0,018 & 0,08 & 0,09 & 0,06 & 0,07 & & 20,12 \\
\hline $\mathrm{P}_{6}$ & 0.14 & 0,16 & 0,20 & 0,14 & 0,16 & 1,00 & 2,00 & 4,00 & 3,00 & 5,00 & 6,00 & 3,00 & 4,00 & 3,00 & 2,00 & 0,02 & \begin{tabular}{|l|l|}
0.02 \\
\end{tabular} & 0,02 & \begin{tabular}{l|l}
0,01 \\
\end{tabular} & 0,01 & 0,05 & 0,12 & 0,16 & 0,15 & 0,15 & 0,01 & $\begin{array}{ll}0,06 \\
\end{array}$ & 0,05 & 0,05 & 0,03 & & 6,25 \\
\hline $\mathrm{P}_{2}$ & 0,25 & 0,50 & 0,14 & 0,25 & 0,25 & 0,50 & 1,00 & 5,00 & 4,00 & 3,0 & 5,00 & 4,00 & 3,00 & 2,00 & 3,00 & 0,04 & 0,06 & 0,01 & 0,02 & 0,02 & 0,0 & 0,0 & 0,20 & 0,20 & 0,09 & 0,01 & $\begin{array}{ll}0,04 \\
\end{array}$ & & & 0,04 & & 8,16 \\
\hline 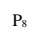 & 0,33 & 0,25 & 0,25 & 0,33 & 0,33 & 0,25 & 0,20 & 1,00 & 2,00 & 3,00 & 4,00 & 5,00 & 3,00 & 2,00 & 4,00 & 0,05 & 0,03 & 0,02 & 0,02 & 0,02 & 0,01 & 0,01 & 0,04 & 0,10 & 0,09 & 0,013 & 0,04 & 0,09 & 0,03 & 0,06 & & 5,50 \\
\hline $\mathrm{P}_{\theta}$ & 0,25 & 0,20 & 0,33 & 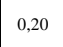 & 0,20 & 0,33 & 0,25 & 0,50 & 1,00 & 3,00 & 5,00 & 4,00 & 6,00 & 5,00 & 6,00 & 0,04 & 0,02 & 0,03 & 0,01 & 0,01 & 0,01 & 0,01 & 0,02 & 0,05 & 0,09 & 0,01 & 0,10 & 0,07 & 0,08 & 0,09 & & 2.80 \\
\hline$P_{10}$ & 0,20 & 0,14 & 0,12 & 0,25 & 0,16 & 0,20 & 0,33 & 0,33 & 0,33 & 1,00 & 4,00 & 3,00 & 2,00 & 5,00 & 3,00 & 0,03 & 0,01 & 0,01 & 0,02 & 0,01 & 0,01 & 0,02 & 0,01 & 0,01 & 0,03 & 0,013 & 0,10 & 0,05 & 0,08 & 0,04 & & 14,66 \\
\hline $\mathrm{P}_{\mathrm{u}}$ & 0,33 & 0,25 & 0,20 & 0 & 0,14 & 0,16 & 0,20 & 0,25 & 0,20 & 0,25 & 1,00 & 2.00 & 3,00 & 3,00 & 4,00 & 0,05 & \begin{tabular}{|l|}
0,03 \\
\end{tabular} & 0,02 & 0,01 & 0,01 & 0,008 & 0,01 & 0,01 & 0,01 & 0,007 & 0,01 & 0,06 & 0,03 & 0,05 & 0,06 & & 13,70 \\
\hline $\mathrm{P}_{12}$ & 0.14 & 0,33 & 0,16 & $\begin{array}{l}0,20 \\
\end{array}$ & 0,20 & 0,33 & 0,25 & 0,20 & 0.25 & 0,33 & 0,50 & 1,00 & 2,00 & 3,00 & 2,00 & 0,02 & 0.04 & 0,01 & 0,01 & 0,01 & 0,01 & 0,01 & 0,008 & 0,01 & 0,009 & 0,02 & 0,06 & 0,01 & 0,05 & 0,03 & & 15,78 \\
\hline $\mathrm{P}_{13}$ & 0.50 & 0,16 & 0,33 & 0,33 & 0,33 & 0,25 & 0,33 & 0,33 & 0,16 & 0,50 & 0,33 & 0,50 & 1,00 & 2,00 & 2,00 & 0,08 & \begin{tabular}{|l|}
0,02 \\
\end{tabular} & $0,0,03$ & 0,02 & 0,02 & 0,01 & 0,02 & 0,01 & 0,008 & 0,01 & 0,01 & 0,08 & 0,009 & 0,03 & 0,03 & & 19,00 \\
\hline $\mathrm{P}_{14}$ & 0,25 & 0,20 & 0,20 & \begin{tabular}{|l|l} 
\\
\end{tabular} & 0,25 & 0,33 & 0,50 & 0,50 & 0,20 & 0,20 & 0,33 & 0,33 & 0,50 & 1,00 & 2,00 & 0,04 & 0.02 & 0,02 & 0,04 & 0,02 & 0,01 & 0,03 & 0,02 & 0,01 & 0,006 & 0,008 & 0,02 & 0,006 & 0,01 & 0,03 & & 17,00 \\
\hline$P_{15}$ & 0,20 & 0,33 & 0,50 & 0,25 &, 20 & 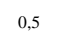 & 0,33 & 25 & 0.16 & 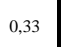 & 0,25 & \begin{tabular}{l|l}
, 50 \\
\end{tabular} & \begin{tabular}{l|l}
0,50 \\
\end{tabular} & 0,50 & 1,00 & 0,03 & \begin{tabular}{|l|}
0,04 \\
\end{tabular} & 0,05 & 0,02 & 0,01 & 0,02 & 0,01 & 0,01 & 0,000 & 0,000 & 0,006 & 0,01 & \begin{tabular}{|l|l|}
0,009 \\
\end{tabular} & 0,008 & 0,01 & & 16,66 \\
\hline
\end{tabular}


Tabel 4. Rancangan Pelatihan

\begin{tabular}{|c|c|c|c|}
\hline $\mathrm{NO}$ & Stasiun & Pelatihan & Materi \\
\hline 1 & Sortasi & Prosedur kerja & $\begin{array}{l}\checkmark \quad \text { Pemilihan buah } \\
\bullet \quad 00 \text { (sangat mentah), belum ada berondolan lepas } \\
\text { dari tandan, warna buah hitam pekat } \\
\bullet \quad 0 \text { (mentah), }<12,5 \text { berondolan/Kg TBS, warna } \\
\text { buah hitam kemerahan }\end{array}$ \\
\hline
\end{tabular}

\begin{tabular}{|c|c|c|c|}
\hline $\mathrm{NO}$ & Stasiun & Pelatihan & Materi \\
\hline 1 & Sortasi & Prosedur kerja & 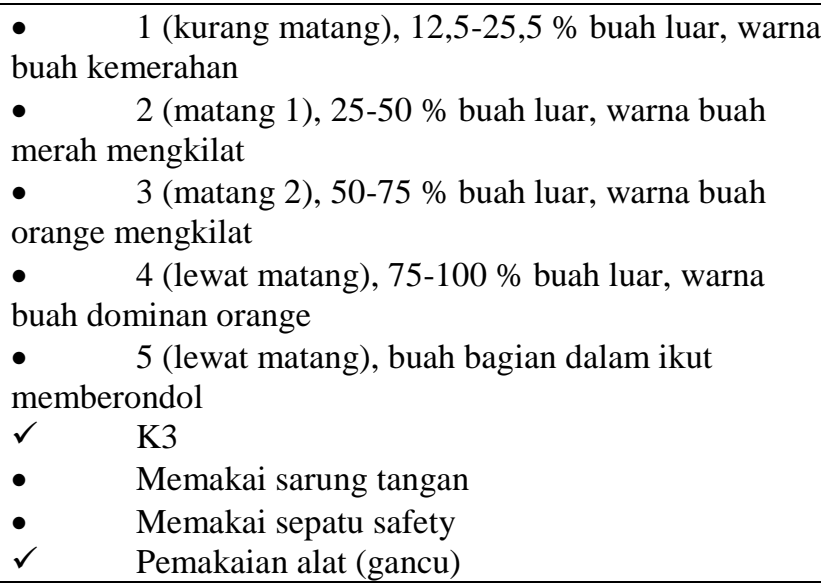 \\
\hline \multirow[t]{2}{*}{2} & \multirow[t]{2}{*}{ Loading Ramp } & Prosedur kerja & $\begin{array}{ll}\checkmark & \text { pemilihan buah yang masuk dalam lori } \\
\checkmark & \text { K3 } \\
\bullet & \text { Memakai sarung tangan } \\
\bullet & \text { Memakai sepatu safety } \\
\checkmark & \text { Pemakaian alat (gancu) } \\
\end{array}$ \\
\hline & & Maintenance & $\begin{array}{l}\checkmark \quad \text { Pengecekan komponen (part) seperti hydraulic, } \\
\text { selang hydraulic agar tidak terjadi kebocoran, flat form } \\
\text { loading ramp periksa las-lasanya apakah ada yang lepas, } \\
\text { serta pintu-pintu yang renggang }\end{array}$ \\
\hline 3 & Sterilizer & Prosedur kerja & 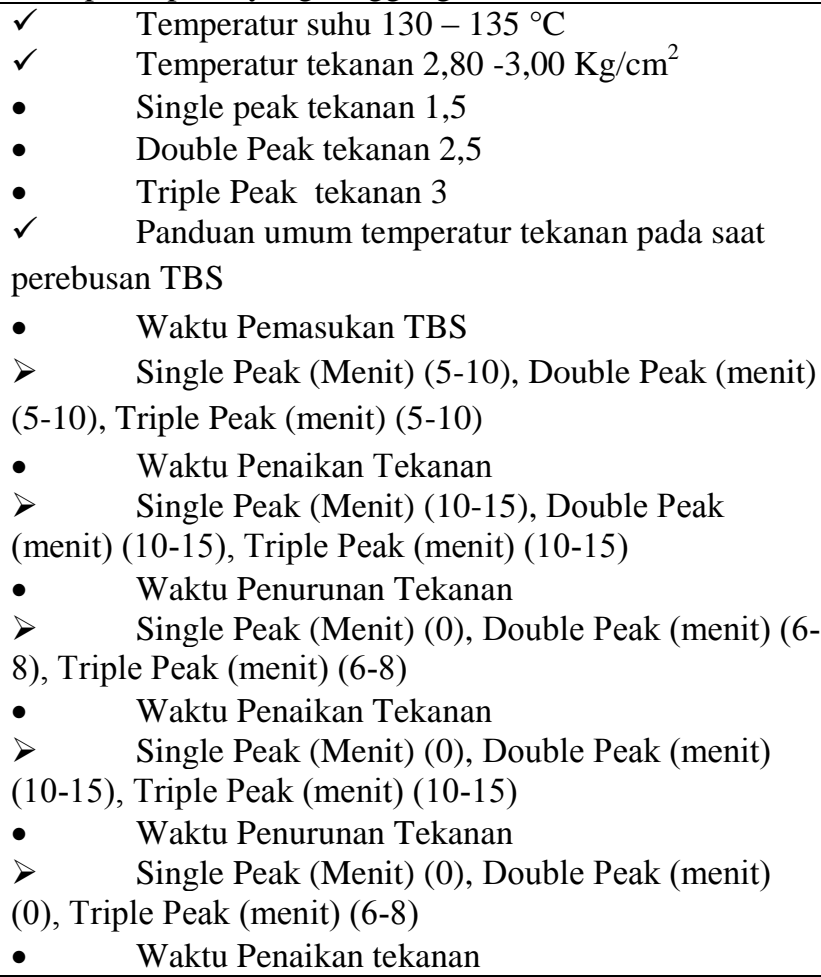 \\
\hline
\end{tabular}




\begin{tabular}{|c|c|c|c|}
\hline & & $\begin{array}{l}>\quad \text { Single Peak (Menit) (0), Double Peak (menit) } \\
(0), \text { Triple Peak (menit) }(10-15)\end{array}$ \\
\hline & & Maintenance & $\begin{array}{l}\checkmark \\
\text { kebocoran seperti pipa blow down steam, pipa outlet } \\
\text { steam, pipa inlet steam } \\
\checkmark \quad \text { Moisture dari kompressor udara harus } \\
\text { dibersihkan minimal seminggu sekali } \\
\checkmark \quad \text { Switch pengaman pada masing-masing pintu } \\
\text { rebusan harus berfungsi dengan baik } \\
\checkmark \quad \text { Bagian dalam tabung sterilizer sebaiknya } \\
\text { dibersihkan setiap hari dan juga areal di sekitar sterilizer }\end{array}$ \\
\hline
\end{tabular}

\begin{tabular}{|c|c|c|c|}
\hline $\mathrm{NO}$ & Stasiun & Pelatihan & Materi \\
\hline \multirow[b]{2}{*}{4} & \multirow[b]{2}{*}{ Hosting crane } & Prosedur kerja & $\begin{array}{ll}\checkmark & \text { Prosedur mengoperasikan mesin } \\
\checkmark & \text { K3 } \\
\bullet & \text { Memakai sarung tangan } \\
\bullet & \text { Memakai sepatu sefety } \\
\bullet & \text { Memakai helm pelindung }\end{array}$ \\
\hline & & Maintenance & $\begin{array}{l}\checkmark \\
\text { pelumasan pada gear box, wire rope, pemeriksaan gigi-gigi } \\
\text { transmisi, chain sprocket, baut-mur dll } \\
\checkmark \quad \text { Bila ditemukan } 3 \text { sampai } 6 \text { kawat yang putus } \\
\text { sebaiknya wire rope segera diganti } \\
\checkmark \quad \text { Pastikan kondisi las-lasan pada sambungan I- } \\
\text { beam baik, bila keausan ketebalan I-beam sudah } \\
\text { mencapai } \pm 30 \% \text { sebaiknya segera diganti. } \\
\checkmark \quad \text { Pemeriksaan kabel instalasi dan panel } \\
\text { elektrikalnya terpasang dengan baik untuk menghindari } \\
\text { terjadinya hubungan singkat }\end{array}$ \\
\hline \multirow[b]{2}{*}{5} & \multirow[b]{2}{*}{ Thressing } & Prosedur kerja & $\begin{array}{ll}\checkmark & \text { Kecepatan putaran pada drum 21 rpm } \\
\checkmark & \text { Menjaga agar oil loss dan kernel loss seoptimal } \\
\text { mungkin } & \end{array}$ \\
\hline & & Maintenance & $\begin{array}{l}\checkmark \\
\text { bersihkan dan periksa kisi-kisi yang meregang, menyempit } \\
\text { atau patah } \\
\checkmark \quad \text { Periksa las-lasan yang retak pada body dan drum, } \\
\text { seperti pada engsel pintu, kisi-kisi, stripper, jari-jari drum, } \\
\text { shaft drum dan lain-lain } \\
\checkmark \quad \text { Lakukan pelumasan pada gear box, bearing- } \\
\text { bearing yang cukup }\end{array}$ \\
\hline \multirow[b]{2}{*}{6} & \multirow[b]{2}{*}{ Digester } & Prosedur kerja & $\begin{array}{ll}\checkmark & \text { Temperatur suhu }\left(90-95^{\circ} \mathrm{C}\right) \\
\checkmark & \text { Temperatur tekanan } 3 \mathrm{Kg} / \mathrm{cm}^{2} \\
\end{array}$ \\
\hline & & Maintenance & $\begin{array}{l}\checkmark \\
\text { bersihkan sisa buah yang menyumbat saluran chute ke } \\
\text { screw press }\end{array}$ \\
\hline \multirow[t]{2}{*}{7} & \multirow[t]{2}{*}{ Screw Press } & Prosedur kerja & $\begin{array}{ll}\checkmark & \text { Temperatur tekanan } 50-70 \mathrm{~kg} / \mathrm{cm}^{2} \\
\bullet & \text { Power yang diperlukan } 19-21 \mathrm{KwH} \text { dengan } \\
\text { putaran } 12-14 \mathrm{rpm} \\
\bullet & \text { Hydraulic Cone } \\
> & \text { Single Stage } 40-50 \text { bar } \\
> & \text { Double presing tekanan pertama } 30-35 \text { bar dan } \\
\text { tekanan kedua } 40-50 \text { bar. } \\
\checkmark \quad \text { Temperatur suhu }\left( \pm 90{ }^{\circ} \mathrm{C}\right)\end{array}$ \\
\hline & & Maintenance & $\begin{array}{l}\text { Pengecekan komponen (part) pada mesin agar tidak terjadi } \\
\text { kebocoran }\end{array}$ \\
\hline 8 & Klarifikasi & Prosedur kerja & Temperatur tekanan pada vakum dryer $\left(90-95{ }^{\circ} \mathrm{C}\right)$ \\
\hline
\end{tabular}




\begin{tabular}{|c|c|c|c|}
\hline & & & $\begin{array}{ll}\checkmark & \text { Temperatur Oil dan Sludge }\left( \pm 90^{\circ} \mathrm{C}\right) \\
\checkmark & \text { Temperatur air delusion }\left( \pm 90^{\circ} \mathrm{C}\right)\end{array}$ \\
\hline & & Maintenance & $\begin{array}{ll}\checkmark & \text { Pengecekan komponen (part) pada mesin agar } \\
\text { tidak terjadi kebocoran terutama pada pipa uap pemanas } \\
\text { pada clean oil tank } \\
\checkmark & \text { Lakukan pembersihan pada nozzle dan holder } \\
\text { nozzle } & \\
\checkmark & \text { Control volume buffer tank agar tetap normal }\end{array}$ \\
\hline \multirow[t]{2}{*}{9} & \multirow[t]{2}{*}{ Boiler } & Prosedur kerja & $\begin{array}{ll}\checkmark & \text { Temperatur tekanan }\left(17-20 \mathrm{Kg} / \mathrm{cm}^{2}\right) \\
\checkmark & \mathrm{K} 3 \\
\bullet & \text { Memakai sarung tangan } \\
\bullet & \text { Memakai sepatu safety } \\
- & \text { Memakai helm pelindung } \\
- & \text { Memakai pelindung telinga } \\
\end{array}$ \\
\hline & & Maintenance & $\begin{array}{l}\checkmark \quad \text { Pengecekan komponen (part) pada mesin agar } \\
\text { tidak terjadi kebocoran, periksa panel-panel kelistrikan, } \\
\text { valve air, valve steam }\end{array}$ \\
\hline
\end{tabular}

